https://doi.org/10.31713/m909

\title{
PROCESSING TECHNOLOGY FOR REFRACTORY GOLD-BEARING ORES
}

\author{
G.E. Askarova \\ teacher, Kazakh National University after Al -Farabi Kazakhstan
}

M.R. Shautenov,

Professor, Professor, Satbayev University, Kazakhstan

K.A. Nogaeva,

Professor, Kyrgyz state University, of geology, mining and development of natural resources named after academician

Usengazy Asanaliev Kyrgyzstan

\begin{abstract}
Gold in nature is most often found in the form of native metal, intermetallic compounds and minerals containing gold, silver, copper, iron, mercury, bismuth, platinum, palladium, iridium, rhodium, and minerals - gold gellurides. In addition, gold is found in the form of compounds with organic acids.

Native gold is never chemically pure and contains up to $50 \%$ impurities. The presence of impurities in gold dramatically affects its quality and properties. For example, arsenic, lead, platinum, cadmium, bismuth, tellurium give gold brittleness, which leads to overgrinding and sludging of gold in the processes of ore preparation. In addition, native gold grains can be coated with films ("shirts") of iron oxides and rock minerals, which significantly complicates the extraction of gold during amalgamation and cyanidation.

Native gold has a high density - from 15.5 to $19.7 \mathrm{t} / \mathrm{m}^{3}$. Gold minerals also have high density. Depending on the size, native gold is classified into coarse (more than 2 $\mathrm{mm}$ ), fine (0.05-2 $\mathrm{mm})$, pulverized (5-50 microns) and finely divided (less than 5 microns). The behavior of native gold grains and gold-bearing minerals in the enrichment processes depends on their composition and dissemination [1].

Gold closely associated with sulphides is well extracted using processes designed to extract sulphides (flotation, depositing, concentration on tables, etc.). Isolation of gold from sulfide products is usually carried out after the destruction of the sulfides themselves by calcination or biochemical method [1].

Schemes and processing regimes of ores substantially depend on the mineral composition of ores, their degradability, the presence or absence of impurities that complicate the extraction of gold, and also on the particle size of gold. These and some other properties of ores are mainly determined by their origin, according to which gold ore deposits are divided into two main groups - primary and placer. About $75 \%$ of gold is mined from primary deposits, and $25 \%$ from alluvial deposits. [1]
\end{abstract}




\section{Introduction}

A very low degree of development is characterized by the gold resource base of the republic. The volume of ore gold mining in Kazakhstan decreased by 2 times compared to 1989, and the degree of development of reserves fell to $0.6 \%$. At the same time, the decline was due to a decrease in production from the actual gold deposits, in which $66 \%$ of all the country's proven gold reserves are located. Active development of this particular part of the gold resource base, and first of all the largest deposits of Vasilkovsky and Bakyrchiksky, can provide a significant increase in gold production in Kazakhstan.

The main problem of large-scale industrial development of these facilities is the difficulty of relatively relatively low-grade ores of gold (from 4 to $9 \mathrm{~g} / \mathrm{t}$ ), requiring the use of expensive efficient and environmentally friendly processing technologies.

The increase in consumption and the cost of precious metals forces gold mining companies to expand their raw materials base and study and develop processes aimed at increasing the extraction of gold from ores and concentrates.

The expansion of the production of precious metals largely depends on the involvement of "refractory" gold-bearing raw materials, including pyrite, arsenopyrite, pyrite-arsenopyrite ores and concentrates, in the sphere of industrial processing. In addition, mixtures of sulfides are often found: sphalerite, galena, chalcopyrite, etc. In all these concentrates, gold is present in various forms: native on the surface of minerals or in their lattice and in the form of intrinsic minerals (tellurides, aurostibnite). Differences in the ratio of these forms of gold, as well as the main minerals, determine a different approach to the processing of concentrates. The practical importance of raw materials of this type has been underestimated previously due to the complexity of the technological extraction of gold.

The persistence of sulfide ores and concentrates is due to microand submicroscopic fineness of gold, its thin impregnation with close association with pyrite and arsenopyrite, which does not allow to obtain high recovery rates when processed by standard methods:

- technological features of gold-containing raw materials determine the choice of technology for its processing;

- the main problem of processing refractory gold-bearing ores is the presence of harmful substances (antimony, arsenic, carbonaceous 
and clay components); free and associated associations of dispersed gold with metal sulfides and oxides, which complicate and impede the extraction of gold from ore;

- practically all known technologies in the head of the technological scheme use gravity methods of enrichment in order to separate free large, medium and small gold;

- methods and apparatuses known in foreign and domestic practice for gravitational ore dressing and removal of clay-sludge fine-grained particles are ineffective;

In recent years, the scope of work on the technological evaluation of gold-bearing ores, as well as on improving the technology for the extraction of precious metals in existing factories, has significantly increased. New methods of processing ores have appeared, requirements for the complexity of using mineral raw materials, as well as for the preservation of the environment and safety precautions, have increased.

Technological studies of gold-bearing ores mainly consist of analyzes and experiments necessary to determine the material composition of ores and the technology for extracting all industrially valuable components from ores. The ultimate goal of the study is to develop a technology for the maximum extraction from ores of all industrially valuable components with the greatest economic effect, subject to the requirements of safety and environmental protection.

In addition to ores, the objects of research are often products of their processing - amalgation and flotation tails, gravity and flotation concentrates, cinder, etc. [2]

The most typical studies are:

research of ores of new deposits at the stage of preliminary exploration;

research of ores of new deposits at the stage of their detailed exploration;

research of ores (or processing products) of exploited deposits.

The research of ores of exploited deposits is extremely diverse in content and volume. In the conditions of existing mines, technological studies are carried out in connection with a change in the nature of ores during mining from lower horizons or new sections of the deposit. Research is being carried out at enterprises and institutes in order to improve the ore processing at existing factories (reducing the loss 
of gold and other recoverable elements, improving the quality of concentrates, increasing the complexity of using raw materials, etc.). To do this, they are testing new enrichment and hydrometallurgical methods, more advanced processing schemes and modes, new reagents and apparatuses. Research is carried out both on a laboratory and semi-industrial and industrial scale. Despite the wide variety of technological research, almost all of them are carried out in the following sequence:

familiarity with the relevant literature and reporting data;

sampling at a field or factory;

preparation of samples for research;

study of the material composition of ores;

technological experiments in the laboratory;

verification and refinement of the results obtained in the laboratory at semi-industrial continuously operating plants or factories;

technical and economic assessment of the results of work and drawing up a report.

Gold ore in terms of material composition are very diverse. In some ores, more than $90 \%$ by weight is quartz; in others, along with quartz, the prevailing minerals are barite (up to 50-60\%), carbonates (up to 20-30\%), iron oxides (up to 25\%), tourmaline (up to 50\%) ) The sulfide content (mainly pyrite, arsenopyrite and pyrotin) ranges from $0-80 \%$. In various quantities, many other minerals are also present in ores, as well as host rocks (schists, granites, diorites, etc.). Ores vary in physical condition. Most of them, after mining, are represented by strong lumpy material, some have the appearance of a loose clay mass with separate pieces. Ores are even more distinguished by the properties of gold and its association with minerals.

When performing technological research, those signs of the material composition that determine the ore processing technology to the greatest extent are of primary interest. These signs are:

the presence in ores along with gold of other useful components having industrial grade;

the content of oxidized minerals in ores as compared to sulfide ones, i.e. the degree of oxidation of ores.

the presence in the ores of components that substantially complicate the processing technology;

the nature of gold in ores, primarily the size of gold particles. 
The presence of other industrially valuable components in ores other than gold is one of the decisive factors in the choice of processing technology. The value of this factor is constantly increasing. This is facilitated, on the one hand, by an increase in the number of useful components with an increase in the depth of extraction of goldbearing ores and, on the other hand, by the requirement for the integrated use of processed raw materials.

According to the degree of oxidation, the ores are divided into primary (sulfide), partially oxidized (mixed) and oxidized.

Currently, primary ores are of the greatest industrial importance; the sulfide content in them ranges from tenths to 80-90\%. In some ores, oxidized minerals are also present, but in such a small amount that they practically do not affect the processing technology.

A characteristic feature of oxidized ores is the presence of iron oxides in them. A number of others contain oxidized minerals of other metals, as well as slimy (clay) components. Sulfides in ores are practically absent or in small quantities and do not affect the technology.

\section{Methods}

The properties of impurity gold differ from the properties of pure gold: impurities reduce the density of gold particles, change the structure, gold becomes less noble in chemical terms. Impurities of iron give gold magnetic properties. Differences in gold composition are noticeably manifested in flotation. Impurities reduce the flotation ability of gold, and the more, the easier they are oxidized. Often, gold particles have surface coatings consisting of oxides of iron and manganese, acanthite, covellite, galena, kaolinite and some other minerals. Coatings, besides natural origin, also appear as a result of mechanical grinding of the gold surface with solid particles during grinding. As a rule, gold with coatings floats worse than gold with a clean surface [2].

The forms of gold release are the most diverse: disseminated, vein-interspersed, vein, spongy, dendritic, scaly, lamellar-nodosum, in oxidized films, porous, magnetic, in intergrowths and others. Flaky and scaly particles float better.

Given the behavior in technological operations, gold particles size is divided into large (larger than 70 microns), small (smaller than 70, but larger than $1 \mathrm{~mm}$ ) and finely dispersed (smaller than $1 \mathrm{~mm}$ ). 
It is advisable to isolate very large (larger than 0.5-0.6 mm), and in finely dispersed - colloidal or submicroscopic (finer than $0.1 \mathrm{~mm}$ ) [2].

The work was carried out using a complex of experimental and analytical research methods, including mathematical modeling methods using computers, mathematical statistics, physical modeling, experimental studies on various scale models and technological studies under production conditions. Physical, physicochemical methods were used in experimental studies Chemical and flotation methods: flotation 'laboratory and industrial tests on ores of various substance.

\section{Experimental research}

Ore gold has about 20 minerals. Of greatest industrial interest is native gold, represented by various metallic particles in size, composition, shape and structure in association with many minerals, most often with quartz, pyrite, arsenopyrite, barite.

Given the behavior in technological operations, gold particles are divided into large particles: large (larger than $70 \mu \mathrm{m}$ ), small (smaller than 70, but larger than $1 \mu \mathrm{m}$ ). Sometimes in large gold it is advisable to allocate very large, larger than $0.5-0.6 \mathrm{~mm}$.

When grinding ores, large gold is freed from bonding with minerals (free gold), is easily captured by gravity enrichment, but does not float well and requires prolonged cyanization.

Coarse-grained gold-bearing minerals, as well as large and small native gold, are well recovered by gravitational processes, but are poorly floated and slowly cyanide.

Dusty and partially fine gold is poorly recovered by gravitational processes, but it floats well and cyanides well if it is not associated with tellurides.

Fine gold is poorly extracted not only by gravitational processes, but also by flotation, if it is not associated with carrier minerals. Such gold is quite satisfactorily extracted only as a result of hydromegallurgical processing.

Fine gold in the crushed ore is partially in a free state, partially in intergrowth with minerals (in aggregates). Free fine gold floats well, dissolves quickly during cyanidation, but is hardly enriched by gravitational methods.

Fine gold in intergrowths also successfully dissolves during cyanidation, and its flotation is determined by the flotation ability of the mineral 
associated with it.

During flotation with sulfhydryl collectors, gold floats well in intergrowths with sulfides, and in intergrowths with non-sulfide minerals only at a certain ratio between the exposed surface of gold and the surface of the mineral associated with it.

Study of gold

The characteristics or properties of ore gold are established by technological tests of ore, mineralogical and phase analyzes, and special studies.

There is no standard technique suitable for all types of ores. Each researcher chooses it depending on the nature of the ore, the purpose of the study and the available equipment.

The most reliable results are obtained using a complex of methods. [3]

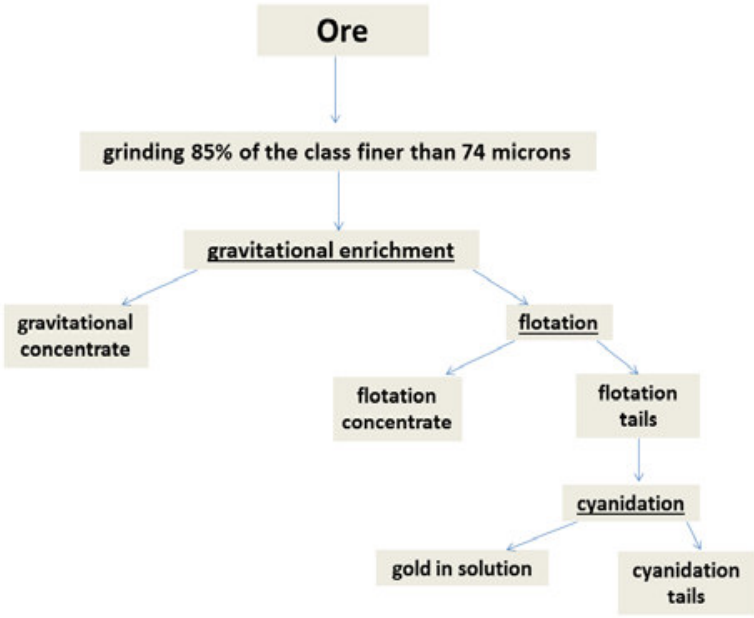

Fig. 1. Gold ore processing scheme

The definition of gold in the particle size classes of ore gives only some idea of the properties of gold. Ores with a grain size of $2 \mathrm{~mm}$ or smaller are divided into classes by dispersion and elutriation. It is advisable to classify ore of such a size at which gold will be extracted by the main method for this ore. Typically, this size is in the range of $90-95 \%-0.315 \mathrm{~mm}$ to $90-95 \%-0.071 \mathrm{~mm}$. Ore weight is divided into classes, for example, $-0.01 ;-0.02 \div+0.01 ;-0.04 \div+0.02 ;-0.071 \div+0.04$; 
$-0.1 \div+0.071 ;-0.2 \div+0,1$ and $+0.2 \mathrm{~mm}$. Each class is weighed and analyzed for gold. If the material of any class is not enough for analysis, then take a second sample of ore and extract the desired class from it. According to the data obtained, it is possible to judge the uniformity (or unevenness) of the gold content in the classes and its division into classes. In large classes there may be free particles of large gold, as well as fine and finely divided gold associated with minerals. In this regard, it is impossible to draw a conclusion about the presence of large gold in ore based on only the gold content of large classes.

The idea of the properties of gold in particle size classes can be substantially supplemented by the establishment of correlation dependencies between the content of gold and other elements in the classes, as well as cyanidation of ore classes. In classes, in addition to gold, it is advisable to determine the content of silver, non-ferrous and rare metals, sulfide sulfur and tellurium. The use of cyanidation as a phase analysis operation to determine the properties of gold is described below.

The object of research is persistent refractory, clay ore weathering crust. The bulk of the free gold particles in this ore have a fineness of less than 20 microns.

The aim of the research is the selection and justification of the combined gravity-flotation method of enrichment of refractory goldbearing raw materials and the hydro and pyrometallurgical method of processing enrichment products based on the study of the technological properties of the feedstock and enrichment products.

For research, two samples of a mixture of ores rich $(5.65 \mathrm{~g} / \mathrm{t})$ and poor ores $(1.2 \mathrm{~g} / \mathrm{t})$ were prepared.

Gravity dressing is designed to extract mainly large gold and, to a lesser extent, fine and gold-containing sulfides from gold-bearing ores. The most common industrial methods are depositing and beneficiation at locks; less commonly used enrichment in drum (pipe) concentrators, in heavy suspensions, on shaking (concentration) tables and in hydrocyclones. All of these methods, except enrichment in drum concentrators, can be tested in laboratory conditions.

Jigging is experienced in the study of almost all gold and complex gold-bearing ores. 
Preparation of the machine for work begins with the installation of the specified parameters - the frequency and amplitude of oscillations of the diaphragm, the size of the mesh openings, the diameter of the fraction, the height of the layer of the fraction, the flow rate of underwater, productivity. When choosing parameters, it is necessary to take into account the following approximate dependencies between these parameters and deposition indices:

the concentrate yield increases with an increase in the amplitude of diaphragm oscillations, a decrease in the consumption of undersieve water, and a decrease in machine load;

Gold recovery with increasing yield of concentrate increases but, as a rule, is not proportional. The indicated dependences are valid only under certain conditions, which can only be established experimentally.

Enrichment on a shaking table is used to clean deposit deposits, to separate free gold and gold-bearing heavy minerals. And also studies were conducted by Kazakhstan hydro-hub [3-5].

Gold flotation (7.5-8.5) must be created by adding soda to the mill (fig.1).

Gold and gold-containing sulfides should be floated with sulfhydryl collectors: xanthates (butyl, amyl, ethyl) and aeroflot. Xanthate consumption $100-150 \mathrm{~g} / \mathrm{t}$. Aeroflot is useful for controlling flotation at a flow rate of $40-50 \mathrm{~g} / \mathrm{t}$. Xanthates are introduced into the pulp in the form of $0.5-1 \%$ aqueous solutions.

If during the flotation of sludge ores a lot of gangue will be transferred to the concentrate, then the preliminary treatment of the pulp with liquid glass should be tested. The consumption of liquid glass is $0.5-1 \mathrm{~kg} / \mathrm{t}$, the processing time is $1-2 \mathrm{~min}$.

It is advisable to test the developed flotation regime on water intended for use in an industrial environment. If the chemical composition of such water is known, then flotation can be carried out with distilled water after adding the appropriate substances to it.

To determine the influence of numerous factors on the flotation results according to the described methodology and to determine the optimal process mode, a significant number of flotation experiments are required. The situation is complicated by the fact that many factors are interrelated, i.e. with a change in one factor, the other also changes. Therefore, even after conducting a large number of experi- 
ments, there is no complete certainty that the developed flotation regime is indeed optimal. In this regard, it is advisable to use mathematical methods of planning experiments and processing the results obtained in studies, which will allow making objective conclusions with a minimum number of experiments.

The flotation concentration regime for ore was selected according to the method of the planned experiment (steep climb) with variables: grinding size, consumption of butyl xanthate and foaming agent T-66 and T-80, consumption of copper sulfate and soda. A fractional replica of the four and five-factor experiment was implemented. According to the experimental results, it was found that it is not possible to obtain flotation tailings of the initial ore with a gold content of less than $1.0 \mathrm{~g} / \mathrm{t}$ with a fineness of ore grinding up to $80-85 \%$ of the class less than $0.074 \mathrm{~mm}$. The output of flotation concentrate depends on the flow rate of the blowing agent and amounted to 8-12\%. In an enlarged experiment, the following results were obtained when returning the intermediate product of cleaning the primary flotation concentrate and concentrate of the 11th flotation:

When consumed in the 1 st flotation

T-80-50 g/t

Xanthate $-175 \mathrm{~g} / \mathrm{t}$.

In the 11th flotation, $\mathrm{T}-80-50 \mathrm{~g} / \mathrm{t}$, xanthate $-175 \mathrm{~g} / \mathrm{t}$ and grinding size $80 \%$ in the class less than $0.074 \mathrm{~mm}$, the yield of flotation concentrate was 11.75 with a gold content of $77.8 \mathrm{~g} / \mathrm{t}$ and gold recovery in concentrate $90.7 \%$. The gold content in the flotation tailings was $1.0 \mathrm{~g} / \mathrm{t}$.

Analysis of gold losses in the flotation tailings by size classes showed that more than $60 \%$ of all gold losses occur in classes larger than 40 microns. With the release of these classes of $43.81 \mathrm{~g} / \mathrm{t}$, the gold content in them was $1.45 \mathrm{~g} / \mathrm{t}$, and the loss with them of gold was $61.55 \%$.

For ore, studies on flotation concentration were carried out on gravity tails with a gold content of $2.4 \mathrm{~g} / \mathrm{t}$ cording to the method of the planned experiment (steep ascent), a fractional replica of a fourfactor experiment with variables was implemented:

Grinding size in a class smaller than $0.074 \mathrm{~mm}\left(X_{1}\right)$;

Consumption of foaming agent T-80 $\left(X_{2}\right)$;

Consumption of butyl xanthate $\left(X_{3}\right)$;

Consumption of copper sulfate $\left(X_{4}\right)$ (table 4-5). 
Table 1

Matrix planning of experiments on the flotation

\begin{tabular}{|c|c|c|c|c|}
\hline \multirow[b]{2}{*}{ Indicators } & \multicolumn{4}{|l|}{ Variable factor } \\
\hline & $\begin{array}{c}\text { size of grinding } \\
\% \text {, smaller than } \\
0.074 \mathrm{CL} .\end{array}$ & $\begin{array}{c}\text { (extraction) } \\
\mathrm{g} / \mathrm{t}\end{array}$ & $\begin{array}{c}\text { butyl } \\
\text { xanthogenate } \mathrm{g} / \mathrm{t}\end{array}$ & $\begin{array}{c}\text { copper } \\
\text { sulphate } g / t\end{array}$ \\
\hline Basic level & 75 & 60 & 125 & 75 \\
\hline $\begin{array}{l}\text { The range of } \\
\text { variation in }\end{array}$ & 10 & 20 & 25 & 75 \\
\hline Top level & 85 & 80 & 150 & 150 \\
\hline Lower level & 65 & 40 & 100 & 0 \\
\hline \multicolumn{5}{|l|}{$\begin{array}{l}\text { № samples } \\
\text { experiments }\end{array}$} \\
\hline 159 & - & - & - & - \\
\hline 160 & + & - & - & - \\
\hline 161 & - & + & - & - \\
\hline 162 & + & + & + & - \\
\hline 163 & - & - & + & + \\
\hline 164 & + & - & + & + \\
\hline 165 & - & + & - & + \\
\hline 166 & + & + & + & + \\
\hline
\end{tabular}

Conditions for conducting experiments

Table 2

\begin{tabular}{l|c|c|c|c}
\hline \multirow{2}{*}{$\begin{array}{c}\text { No samples } \\
\text { experiments }\end{array}$} & $\begin{array}{c}\text { Size of grinding } \\
\text { \%, smaller than } \\
0.074 \text { CL. }\end{array}$ & \multicolumn{3}{|c}{ Reagent consumption, g/t } \\
\cline { 3 - 5 } & T-80 & $\begin{array}{c}\text { butyl } \\
\text { xanthogenate }\end{array}$ & $\begin{array}{c}\text { copper } \\
\text { sulphate }\end{array}$ \\
\hline 159 & 65 & 40 & 100 & 0 \\
\hline 160 & 85 & 40 & 100 & 0 \\
\hline 161 & 65 & 80 & 100 & 0 \\
\hline 162 & 85 & 80 & 150 & 0 \\
\hline 163 & 65 & 40 & 150 & 150 \\
\hline 164 & 85 & 40 & 150 & 150 \\
\hline 165 & 65 & 80 & 100 & 150 \\
\hline 166 & 85 & 80 & 150 & 150 \\
\hline 167 & 65 & 80 & 100 & 0 \\
\hline 168 & 85 & 40 & 150 & 150 \\
\hline 169 & 65 & 40 & 150 & 150 \\
\hline 170 & 85 & 80 & 150 & 150 \\
\hline
\end{tabular}

Table 3

Results of experiments performed on the experiment planning matrix

\begin{tabular}{c|c|c|c|c|c}
\hline $\begin{array}{c}\text { № experiment } \\
\text { numbers }\end{array}$ & Products & $\begin{array}{c}\text { Output, } \\
\%\end{array}$ & $\begin{array}{c}\text { Gold } \\
\text { content, } \\
\mathrm{g} / \mathrm{t}\end{array}$ & $\begin{array}{c}\text { Weight } \\
\text { of gold, } \\
\mathrm{g} / \mathrm{t}\end{array}$ & $\begin{array}{c}\text { Division, } \\
\%\end{array}$ \\
\hline \multirow{3}{*}{1} & Concentrate & 5.81 & 25.1 & 1.458 & 60.72 \\
\cline { 2 - 6 } & Tails & 94.19 & 1.0 & 0.942 & 39.24 \\
\cline { 2 - 6 } & Source & 100 & 2.4 & 2.4 & 100 \\
\hline
\end{tabular}


Continuation of table. 3

\begin{tabular}{|c|c|c|c|c|c|}
\hline \multirow{3}{*}{2} & Concentrate & 5.88 & 24.8 & 1.459 & 60.78 \\
\hline & Tails & 94.12 & 1.0 & 0.941 & 39.22 \\
\hline & Source & 100 & 2.4 & 2.4 & 100 \\
\hline \multirow{3}{*}{3} & Concentrate & 6.81 & 22.91 & 1.56 & 65.0 \\
\hline & Tails & 93.19 & 0.9 & 0.84 & 35.0. \\
\hline & Source & 100 & 2.4 & 2.4 & 100 \\
\hline \multirow{3}{*}{4} & Concentrate & 8.5 & 16.4 & 1.3935 & 58.06 \\
\hline & Tails & 91.5 & 1.1 & 1.0065 & 41.94 \\
\hline & Source & 100 & 2.4 & 2.4 & 100 \\
\hline \multirow{3}{*}{5} & Concentrate & 9.63 & 13.7 & 1.316 & 54.83 \\
\hline & Tails & 90.37 & 1.2 & 1.084 & 45.17 \\
\hline & Source & 100 & 2.4 & 2.4 & 100 \\
\hline \multirow{3}{*}{6} & Concentrate & 8.79 & 20.0 & 1.762 & 73.42 \\
\hline & Tails & 91.21 & 0.7 & 0.638 & 26.58 \\
\hline & Source & 100 & 2.4 & 2.4 & 100 \\
\hline \multirow{3}{*}{7} & Concentrate & 9.94 & 16.0 & 1.59 & 66.25 \\
\hline & Tails & 90.06 & 0.9 & 0.81 & 33.75 \\
\hline & Source & 100 & 2.4 & 2.4 & 100 \\
\hline \multirow{3}{*}{8} & Concentrate & 9.27 & 17 & 1.58 & 65.8 \\
\hline & Tails & 90.73 & 0.9 & 0.82 & 34.2 \\
\hline & Source & 100 & 2.4 & 2.4 & 100 \\
\hline \multirow{3}{*}{9} & Concentrate & 6.55 & 19.5 & 1.279 & 53.29 \\
\hline & Tails & 93.45 & 1.2 & 1.121 & 46.71 \\
\hline & Source & 100 & 2.4 & 2.4 & 100 \\
\hline \multirow{3}{*}{10} & Concentrate & 8.4 & 11.1 & 0.934 & 38.92 \\
\hline & Tails & 91.6 & 1.6 & 1.466 & 61.08 \\
\hline & Source & 100 & 2.4 & 2.4 & 100 \\
\hline \multirow{3}{*}{11} & Concentrate & 8.76 & 17.0 & 1.488 & 61.98 \\
\hline & Tails & 91.24 & 1.0 & 0.912 & 38.02 \\
\hline & Source & 100 & 2.4 & 2.4 & 100 \\
\hline \multirow{3}{*}{12} & Concentrate & 9.59 & 11.8 & 1.59 & 66.1 \\
\hline & Tails & 90.41 & 0.9 & 0.81 & 33.9 \\
\hline & Source & 100 & 2.4 & 2.4 & 100 \\
\hline
\end{tabular}

\section{Results and discussion}

The reproducibility of experiments is estimated by variance

$$
\sigma_{x}^{2}=\frac{\sum_{i=1}^{n}\left(X_{i}-X^{-}\right)}{N-1}
$$

Where $X \leftarrow$ is the average value of the optimization parameter; $X_{i}$ is the value of the optimization parameter of an individual repetition; $N$ is the number of experiments, 
Table 4

Variance of experiments (has been compiled to calculate the variance)

\begin{tabular}{|c|c|c|c|c|}
\hline № samples & $E_{1}$ & $E_{2}$ & $E_{1}+E_{2} / 2$ & $\sigma_{x}^{2}$ \\
\hline 159 & 60.76 & - & 60.76 & - \\
\hline 160 & 60.78 & - & 60.78 & - \\
\hline 167 & 65.0 & 53.29 & 59.15 & 68.44 \\
\hline 162 & 58.06 & - & 58.056 & - \\
\hline 168 & 54.83 & 38.92 & 46.88 & 126.405 \\
\hline 169 & 73.42 & 61.98 & 67.7 & 65.37 \\
\hline 165 & 66.25 & - & 66.25 & - \\
\hline 166 & 65.8 & 66.1 & 65.95 & 0.045 \\
\hline & & & $\Sigma=481.53$ & $\Sigma=260.26$ \\
\hline
\end{tabular}

Combined processing technology of the studied ore. In order to more fully evaluate the use of the cyanide process of the ore under study, in addition to the research plan, enlarged laboratory experiments were conducted to cyanide the initial ore, gravity tails and flotation tails.[4-9]

The experiments included cyanidation in the presence of sorbents: AM-2B resin during cyanidation of ore or gravity tails and flotation tails and activated carbon during cyanidation of gravity and flotation concentrates and their mixtures.

Table 5

The effect of the duration of cyanidation on the extraction of gold from their tailings flotation of ore 3

\begin{tabular}{l|c|c|c|c|c|c}
\hline \multirow{2}{*}{$\begin{array}{l}\text { Conditions and } \\
\text { Results }\end{array}$} & \multicolumn{5}{|c}{ № of experiments } \\
\cline { 2 - 7 } $\begin{array}{l}\text { Cyanization duration, } \\
\text { hour }\end{array}$ & 2 & 49 & 6 & 8 & 12 & 18 \\
\hline Pulp density. \% tv & 40 & 40 & 40 & 40 & 40 & 40 \\
\hline $\begin{array}{l}\text { The concentration of } \\
\text { cyanide,\% }\end{array}$ & & & & & \\
\hline Initial & 0.045 & 0.045 & 0.045 & 0.045 & 0.045 & 0.045 \\
\hline the ultimate & 0.035 & 0.035 & 0.035 & 0.035 & 0.035 & 0.035 \\
\hline $\begin{array}{l}\text { Cyanide consumption. } \\
\text { kg/t }\end{array}$ & 0.15 & 0.15 & 0.15 & 0.15 & 0.15 & 0.15 \\
\hline $\begin{array}{l}\text { Lime consumption, } \\
\text { kg/t }\end{array}$ & 1.0 & 1.0 & 1.0 & 1.0 & 1.0 & 1.0 \\
\hline Sorbent, g & & 1.0 & 1.0 & 1.0 & 1.0 & 1.0 \\
\hline $\begin{array}{l}\text { Gold Content, g/t } \\
\text { in the original product }\end{array}$ & 0.8 & 0.8 & 0.8 & 0.8 & 0.8 & 0.8 \\
\hline in sorption tails & 12.5 & 25.0 & 37.5 & 43.75 & 43.75 & 43.75 \\
\hline ld recovery,\% & & & & & \\
\hline
\end{tabular}




\section{Conclusion}

Based on the results of the studies, the following options for ore processing schemes are recommended:

Isolation of large free gold and sulfides in the grinding cyclesorption cyanidation of the tails of gravity. Technological mode:

- the size of ore grinding $80-85 \%$ of the class is smaller than 0.074 $\mathrm{mm}$;

- Duration of cyanide 4-6 hours;

- Duration of sorption cyanide -15 hours;

The consolidated (balance) experiment according to the scheme in Figure 1 was performed under the following conditions: - the size of the grinding of gravity tails in the 1 st flotation- $65 \%$ CL. smaller than $0.074 \mathrm{~mm}$;

- fineness of the tailings of the $2^{\text {nd }}$ flotation $77.9 \%$ CL. finer than $0.050 \mathrm{~mm}$;

- the mode of the 1st flotation: - duration of flotation - 5 min;

- consumption of T-80-60 g/t;

- consumption of xanthogenate - $75 \mathrm{~g} / \mathrm{t}$;

- the mode of the $2^{\text {nd }}$ flotation: - duration of flotation - $10 \mathrm{~min}$;

- consumption T-80-20 g/t;

- consumption of xanthogenate - $25 \mathrm{~g} / \mathrm{t}$;

- 3rd flotation mode: - duration of flotation - $15 \mathrm{~min}$;

- consumption T-80 - $20 \mathrm{~g} / \mathrm{t}$;

- consumption of xanthogenate - $50 \mathrm{~g} / \mathrm{t}$. 
The research was carried out within the framework of the Project GF MES RK «Research and instrumentation of the processing technology of refractory arsenic-sulfide gold-bearing ore of the Kazakhstan deposit» №0210РК00912

Reference

1. A.S. Seidaly, E.A. Lazarova, I.A.Semiletova Gold processing and extraction from refractory gold-bearing ores-Almaty, KazgosINTI, 2001.-56c

2. V.I. Zelenkova Methodology for the study of gold-bearing ores. M., Nedra 1978

3. Taggart, A.F. (1933). Handbook of mineral processing. M.-L.: State scientific and technical mining and geological and petroleum publishing house, 1933

4. O.S. Bogdanova. Handbook of ore dressing. Main processes. (1983). Mocow: Nedra

5. L.V. Chugayev. (1987). Metallurgy of precious metals. Mocow: Metallurgy

6. Kotlyar, Y.A., Meretukov M.L. (2002). Metallurgy of precious metals.Moskow: Metallurgy

7. Meretukov, I.N., Orlov, A.M. (1991). Metallurgy of noble metals. Foreign experience. Moscow: Metallurgy

8. Ladeishikov, V.V. (1968). Extraction of gold from refractory ores and concentrates. Moscow: Nedra

9. Ladeishikov, V.V. (1999). Technology of extracting gold and silver from refractory ores. Irkutsk: JSC "Irgiredmet". 